\title{
Gestão de políticas sociais: a importância das articulações institucionais e setoriais em programas de segurança alimentar e nutricional
}

Social policies management: the importance of institutional and sectors articulations in food safety programs

Luiz Antonio Staub Mafra ${ }^{1}$

Flavia Luciana Naves²

\section{Resumo}

A descentralização de responsabilidades e de poder para os municípios executarem muitas das políticas que antes estavam a cargo do governo federal demonstra que tal processo, mesmo representando avanços na democratização, acarretou dificuldades para as prefeituras, ainda maiores se considerada a complexidade inerente às políticas sociais. A elaboração e implementação de políticas de segurança alimentar e nutricional (SAN) - tema que tem se destacado crescentemente no âmbito de atuação do poder público, em especial dos governos municipais - acarretam muitos desafios e têm demandado dos gestores públicos a construção de articulações específicas entre setores e instâncias do próprio governo, da sociedade civil e da esfera privada. Neste artigo, procura-se contribuir na discussão sobre a importância da construção destes arranjos mediante estudo de caso realizado no município de Belo Horizonte.

Palavras-chave: articulações; políticas públicas; segurança alimentar.

Abstract

The decentralization of both responsibilities and power for the cities to implement some of the policies that were exclusive responsibility of the federal government before shows that this process, even when bringing advances in what is related to the democratization, resulted in difficulties for local governments, especially when considering the complexities that are inherent to social policies. The formulation and implementation of programs of food and nutritional safety, a matter that has been increasingly emphasized in the realm of public policies, especially of city government, generates many challenges, forcing the governors to create specific articulations among government's sectors and parts, civil society and private sphere. The objective of the article is to contribute for the discussion about the importance of the construction of these arrangements from a case study carried out in the city of Belo Horizonte.

Key words: articulation; public policies; food safety.

\footnotetext{
${ }^{1}$ Doutor em Ciências Sociais pelo Programa de Pós-graduação em Desenvolvimento,Agricultura e Sociedade - Universidade Federal Rural do Rio de Janeiro CPDA/UFRRJ.Professor da Escola de Ciências Humanas e Sociais (Pólo Volta Redonda) - Universidade Federal Fluminense. Endereço: Av. dos Trabalhadores, 420 - Vila Santa Cecília - Volta Redonda/Rio de Janeiro - Brasil - CEP:27255-125. E-mail:lasmafra@navinet.com.br

${ }^{2}$ Doutora em Ciências Sociais pelo Programa de Pós-graduação em Desenvolvimento,Agricultura e Sociedade - Universidade Federal Rural do Rio de Janeiro - CPDA/UFRRJ.Professora no Departamento de Administração na Universidade de Lavras. Endereço: Departamento de Administração e Economia DAE/UFLA - Caixa Postal 3037 - Campus Universitário - Lavras - Minas Gerais - Brasil - CEP: 37200-000. E-mail: flanaves@ufla.br

Artigo submetido em janeiro de 2007 e aceito em março de 2008
} 


\section{Introdução}

Os meandros da construção de políticas públicas são bastante complexos. Se, em sua elaboração e na definição de prioridades e conteúdos, há muitas dificuldades, o processo de implementação envolve igualmente muitos conflitos. O desenho de tais políticas deve levar em conta as necessidades das populações que pretende atender, com atenção à disponibilidade de recursos e restrições de diversos tipos. Também a tradução de uma concepção de política em ações e práticas enfrenta problemas que podem desvirtuar sua proposição original ou, mesmo, inviabilizar sua execução.

Tais dificuldades ficam evidentes, por exemplo, na elaboração e na implementação de políticas sociais, cuja demanda cresce constantemente no país, com destaque especial, nos últimos anos, para políticas de segurança alimentar e nutricional (SAN). Esta área vem ganhando espaço tanto na esfera governamental como no debate popular, em parte, devido às gritantes evidências de fome e desnutrição em diversas regiões do país e também pelo lugar de destaque defendido pelo governo federal para políticas e ações nesta área.

As ações concretas que compõem tais políticas são muito diversificadas, envolvem setores públicos e privados, bem como diversas áreas do conhecimento e dependem de grande capilaridade para serem efetivas, sejam políticas federais, estaduais ou municipais. Embora a ênfase recente esteja em políticas do âmbito federal, com o processo de descentralização, têm sido repassadas, cada vez mais, aos municípios, responsabilidades pela operacionalização das políticas referentes à segurança alimentar. Trata-se, mesmo, de uma temática que já não pode ser evitada pelos gestores municipais na medida em que os problemas relativos à fome e à desnutrição, dificuldade de acesso à alimentação tornam-se evidentes nos espaços mais localizados.

A elaboração e implementação de tais políticas passaram a ser um desafio às administrações municipais, que têm buscado articulações entre setores da própria administração e com diferentes instituições públicas e da sociedade civil. Os caminhos para isso, os arranjos possíveis, são específicos para cada localidade, mas, os aprendizados de cada experiência podem e devem ser evidenciados.

Isto pôde ser percebido por meio de pesquisa de caráter qualitativo realizada no município de Belo Horizonte, no ano de 2004. O foco concentrou-se especialmente sobre o órgão gestor da política de segurança alimentar e nutricional do município ao longo da década anterior, a Secretaria Municipal de Abastecimento (SMAB). O estudo de caso - "um tipo de pesquisa especialmente adequado quando se quer focar problemas práticos, decorrentes das intrincadas situações individuais e sociais presentes nas atividades, nos procedimentos e nas interações cotidianas" (GODOY, 2006, p. 121) - foi uma escolha coerente com os objetivos desta pesquisa, na qual se empregaram métodos como análise documental, entrevistas formais e informais e observação não participante.

$\mathrm{Na}$ análise documental foram utilizados boletins oficiais, relatórios, informativos e pesquisas anteriormente realizadas sobre o mesmo tema em Belo Horizonte. Foram feitas entrevistas informais e formais, orientadas por questionários semi-estruturados, com gestores dos programas de SAN, permissionários, ex-integrantes da equipe gestora e membros de outros setores da administração municipal que contribuíram na implementação de tais processos.

Nas visitas à SMAB e principalmente aos permissionários, a observação não participante foi importante para caracterizar o relacionamento destes agentes com representantes dos órgãos gestores e destes com os consumidores.

Este desenho metodológico permitiu a compreensão dos processos de construção de articulações institucionais e setoriais que caracterizam a política de segurança alimentar e nutricional do município de Belo Horizonte, em especial os programas de regulação de mercado e de assistência alimentar, que serão discutidos a seguir. 


\section{A complexidade da gestão de políticas públicas municipais}

Há uma crescente ênfase na gestão das políticas públicas municipais. O processo de descentralização que vem ocorrendo ao longo das últimas décadas, no Brasil, leva a que este espaço, antes diretamente atrelado às decisões de outros escalões da política, ganhe destaque, mais responsabilidades e alguma autonomia.

Silva (2000) afirma que a descentralização pode ser definida, de forma geral, como a transferência de poder, para planejar, gerir, executar e tomar decisões, do nível nacional para instâncias subnacionais. No âmbito das políticas públicas, a descentralização significa um processo de reestruturação interna no aparelho do Estado, que perpassa as várias esferas de governo, envolvendo aspectos políticos, administrativos, técnicos e financeiros.

No Brasil, segundo este autor, diferentemente dos países membros da OCDE (Organização para Cooperação e o Desenvolvimento Econômico), o processo de descentralização esteve, no período recente, bastante condicionado pela democratização e pela crise fiscal e financeira de um Estado autoritário, no bojo de transformações da federação brasileira (SILVA 2000, apud FIORI, 1994; ALMEIDA, 1994). SILVA (2000) destaca ainda que a luta pelo fim do Estado autoritário e de seus mecanismos e arranjos de poder fortemente centralizadores fez a descentralização tornar-se, para muitos, sinônimo incontestável de democracia. Especialmente na área social, o perfil da intervenção estatal prevalecente no período autoritário - centralizado, fragmentado organizacionalmente e excludente no que tange às comunidades mais pobres da população induziu à crença de que a descentralização levaria, por si só, à maior eqüidade na distribuição de bens e serviços e à maior eficiência na operação do aparato estatal.

A descentralização ganha força com a idéia de que é preciso conferir mais poder àqueles que estão perto dos cidadãos e de suas necessidades, mas, pode-se dizer que tal processo colocou em evidência tanto as possibilidades e oportunidades existentes neste espaço como os problemas, conflitos e obstáculos que se construíram com base nas especificidades locais ao longo da história e da formação da cultura política local.

Esta crença vai sofrer impactos na prática do processo de municipalização quando ficam evidentes as dificuldades de implementação das ações e políticas necessárias para atender a esta população próxima, dando conteúdo, forma e existência às políticas sociais.

Para Abranches et al. (1998), a política social é parte do processo estatal de alocação e distribuição de valores e está no centro do confronto entre interesses de grupos e classes, cujo objetivo é a reapropriação de recursos, extraídos dos diversos segmentos sociais, em proporção distinta, através da tributação. Essa tensão nas disputas pela alocação dos recursos revigora-se com o projeto de reforma do Estado e liberalização do mercado, cujas ações foram prenunciadas pela Constituição de 1988 e retomadas na década de 1990, procedendo-se a uma série de privatizações, principalmente das estruturas produtivas, e ao enxugamento do aparato estatal com a intenção de reformar o Estado. ${ }^{1}$

A reforma significaria reduzir o Estado, limitar suas funções como produtor de bens e serviços e, em menor extensão, como regulador, mas, por outro lado, segundo, Bresser Pereira (1999), Ministro da Administração e Reforma do Estado no Governo FHC, implicaria também ampliar suas funções no financiamento de atividades que envolvam externalidades ou direitos humanos básicos e na promoção da competitividade internacional das indústrias locais.

No entanto, as funções de financiamento nem sempre são assumidas em sua totalidade pelo Governo Federal. Silva (2000, apud ABRUCIO e COUTO, 1996) lembra que, na década de 1990, houve aumento significativo dos gastos dos municípios com saúde e educação, o que demonstra o quanto essas unidades assumiram o papel de welfare, enquanto a União, inversamente, se distanciou paulatinamente da atuação nestas áreas, com algumas exceções. 
Uma vez assumindo um novo papel, os municípios precisam mudar suas estruturas administrativas, capacitarse financeiramente e mudar o relacionamento com o setor privado e organizações da sociedade civil como forma de viabilizar a operacionalização de suas políticas sociais.

Apesar das transferências de recursos da união para os municípios, tal medida não se mostrou suficiente para o pleno atendimento das demandas por políticas sociais. Neste cenário, a focalização torna-se uma necessidade para fazer com que os recursos disponíveis possam chegar pelo menos naqueles que mais necessitam. É o que Santos $(1998,37)$ considera como "escolhas trágicas", referindo-se ao fato de que as escolhas entre diferentes políticas sociais "escapam ao cálculo econômico e ingressam na contabilidade ética, no cerne do conflito entre valores, no trágico comércio entre o bem e o mal".

Focalizar significa escolher com base em alguns critérios os programas e políticas sociais e, conseqüentemente, pessoas e grupos a serem beneficiados. Entretanto, essas escolhas implicam atender a determinados grupos em detrimento de outros. Farah (2001) considera que a focalização é incorporada pelo reconhecimento da necessidade de se estabelecerem prioridades de ação em contexto de limites de recursos e pela compreensão de que é preciso atender de forma dirigida alguns segmentos da população que vivem situações de carência social extrema. No entanto, lembra a autora, as políticas seletivas devem ser entendidas como complementares às políticas universais de caráter redistributivo e às políticas de desenvolvimento orientadas para a superação de desigualdades estruturais.

Para Draibe (1998), a focalização constitui um dos ingredientes centrais da proposta de reforma dos programas sociais na perspectiva neoliberal. Consistente na idéia de redução do Estado e de estímulo ao mercado, trata-se de restringir a ação social do Estado de forma a concentrá-la em determinados programas e segmentos da população. O gasto social só se justifica, assim, para os muito pobres e em programas considerados essenciais e não passíveis de oferta no mercado.

Um problema da focalização é quando esta passa a ser utilizada para justificar redução nos gastos públicos. Focalizar um grupo específico para melhor aproveitamento dos recursos e da efetividade da ação pode ser uma alternativa às restrições operacionais e orçamentárias, mas a restrição do acesso de pessoas pode induzir a alguns erros, como excluir, entre os beneficiários, aqueles que realmente necessitem do amparo do Estado.

Assim, focalização implica definir quem necessita destes benefícios. Entretanto, os critérios de seleção e o processo de monitoramento e controle das ações focalizadas são onerosos e demandam um grande contingente para as atividades de supervisão e monitoramento.

Potencialidades e dificuldades associadas ao processo de focalização devem ser consideradas. Para Burlandy (2003), os aspectos positivos referem-se à definição e destinação de recursos para grupos prioritários, adequando-os às demandas. Os desafios giram em torno dos custos econômicos, sociais e políticos relacionados à definição dos beneficiários, que aumentam à medida que crescem os níveis de diferenciação das demandas; da capacidade técnico-institucional disponível; da dimensão da vulnerabilidade frente aos recursos existentes; da disponibilidade de instrumentos metodológicos necessários a uma adequada focalização; da não estigmatização dos beneficiários; da natureza dos processos decisórios e da cisão entre os que precisam e aqueles que não precisam.

Pinho e Santana (2000) apontam a necessidade crescente de formas de negociação que incorporem efetivamente à discussão os setores a serem atingidos pelas políticas municipais, bem como da construção de novas parcerias com o setor privado, visando ao desenvolvimento econômico local.

Tudo isso precisa ainda tornar-se compatível com a eficácia destas políticas, levando a um investimento maior em inovações administrativas e maior profissionalização nas gestões municipais. Tais arranjos e inovações são feitos também para abarcar novas áreas de interesse, muitas delas temas específicos de interesse social.

Pinho e Santana (2000) afirmam, ainda, que é possível identificar, no âmbito da gestão dos municípios, o abandono de ações ligadas à "maquiagem" urbana, o que os leva a assumir "questões de maior complexidade", 
como intervenções na área de abastecimento, envolvendo produção, circulação, comercialização e consumo, com reflexos na melhoria da qualidade de vida e na distribuição de renda. $\mathrm{O}$ abastecimento, por exemplo, começa a ser visto como componente da política de desenvolvimento municipal.

É exatamente este tipo de política do âmbito municipal que interessa, neste artigo, e que nos leva a fazer uma breve discussão sobre a complexidade que envolve também a noção de segurança alimentar e nutricional.

\section{Uma rápida aproximação ao tema da segurança alimentar e nutricional}

O surgimento do termo 'segurança alimentar' está ligado a questões relativas à estratégia nacional, com ênfase, por exemplo, em problemas de desabastecimento em decorrência de eventuais crises externas. Dessa forma, as políticas de segurança alimentar tinham, a princípio, um sentido de maximizar a auto-suficiência na produção de alimentos, o controle e a manutenção de estoques para casos emergenciais. Mas, ao longo do tempo, a noção de segurança alimentar vem incorporando elementos que evidenciam as diversas dificuldades de acesso aos alimentos, principalmente das populações mais vulneráveis à fome e à desnutrição.

As políticas de abastecimento alimentar foram consideradas, durante muito tempo, suficientes para solucionar os problemas de acesso aos alimentos. Entretanto, para Lavinas e Maluf (1992) a noção de segurança alimentar possibilita redefinir, com maior pertinência e amplitude, o entendimento usual acerca do que é o abastecimento, além de resgatar um direito fundamental de todo indivíduo, que é o de estar protegido contra a fome.

Além dos problemas relacionados a produção, distribuição e consumo que interferem diretamente no acesso da população aos alimentos, alguns autores atribuem à problemática da segurança alimentar um forte caráter político. Dreze e Sen (1989) acreditam que a fome do mundo moderno é muito mais uma questão política, sanável por uma decisão dos governos de garantir o direito de acesso aos alimentos a todos os cidadãos por meio de políticas redistributivas que reduzissem as desigualdades entre diversos segmentos e estratos sociais.

Não sendo uma questão apenas individual, mas de interesse coletivo e público, torna-se essencial o desenvolvimento de políticas efetivas capazes de assegurar a promoção e a garantia do acesso da população a uma alimentação adequada quantitativa e qualitativamente, em bases sustentáveis, como reforça o conceito difundido pela representação brasileira apresentada à Cúpula Mundial da Alimentação. ${ }^{2}$

Para Wilson (2002), as fomes coletivas são a manifestação final do fracasso do governo em servir e proteger seus cidadãos e representam também uma ruptura na habilidade da comunidade em proteger a si mesma e os membros mais frágeis. Esta afirmação associa o problema da fome e da insegurança alimentar não só à capacidade do indivíduo em se alimentar, mas também a um problema da sociedade e principalmente do Estado em garantir uma alimentação adequada à população, seja pelo funcionamento da economia ou como provedor direto às famílias que não conseguem o acesso via mercado.

Entretanto, ao se passar à prática da elaboração e implementação das políticas públicas, inúmeras dificuldades apresentam-se para que sejam efetivas em contribuir de maneira sistemática ao acesso da população a alimentos de forma regular, em quantidade e qualidade necessárias à plena satisfação de suas necessidades nutricionais, respeitando a cultura local e os hábitos de consumo.

Estas dificuldades têm se apresentado como um desafio aos municípios, que mais diretamente recebem pressão popular pelos problemas que a fome e a desnutrição representam, além de serem também responsáveis pela gestão de programas federais na área alimentar, atribuição que lhes foi conferida com o processo de descentralização das políticas públicas. Dessa forma, os municípios têm se tornado um local privilegiado para o desenvolvimento de projetos, ações e políticas na área de SAN, não só pelas responsabilidades atribuídas às administrações municipais, mas também pela proximidade com as demandas sociais.

Embora as responsabilidades e obrigações dos municípios em relação à SAN, muitas vezes, não sejam suficientemente claras (com regulamentações específicas), há um espaço a ser explorado na esfera municipal 
para o desenvolvimento de ações que contribuam para melhorar o acesso das populações mais vulneráveis a uma alimentação de qualidade.

Maluf (2001) destaca cinco diretrizes que devem orientar a formulação de políticas municipais de segurança alimentar: a) promoção da produção rural e urbana e a comercialização de alimentos em bases socialmente equiitativas; b) ampliação do acesso a uma alimentação de qualidade e regulação das condições em que os alimentos são disponibilizados à população; c) promoção da educação alimentar e da organização dos consumidores na defesa dos seus direitos; d) universalizar e assegurar a qualidade dos programas alimentares com caráter suplementar ou emergencial dirigidos a grupos populacionais específicos; e) estímulo à participação da sociedade civil na formulação e na implementação da política de segurança alimentar e apoio às iniciativas não-governamentais.

Por estas orientações, a composição de uma política de SAN não é tarefa simples, sua execução acaba envolvendo aparatos e setores com políticas e estruturas frequientemente independentes, tais como as áreas de saúde, educação, saneamento básico, geração de emprego e renda, produção agrícola etc. Se tal situação pode gerar confusão - o que ocorre freqüentemente -, também pode se apresentar como uma alternativa à solução de problemas que possuem raízes similares, como é o caso de saúde e SAN, por exemplo. Tais vinculações entre as áreas (o que não significa que haja relações institucionalizadas entre setores e políticas específicas), construídas da prática, podem ser identificadas em quaisquer localidades, independente do conteúdo e formato das políticas adotadas.

Apesar da flexibilidade no estabelecimento das políticas de abastecimento e segurança alimentar nos municípios, tais práticas colocam o poder público em relação direta - e, muitas vezes, em confronto - com a iniciativa privada e com setores da sociedade civil.

Uma das tradicionais frentes de atuação das políticas de SAN na esfera municipal é o abastecimento alimentar, principalmente no que se refere às possibilidades de regulação dos mercados locais de alimentos básicos e dos hortigranjeiros. Para Lavinas e Maluf $(1992,65)$, é indispensável recuperar a dimensão pública da questão alimentar e, sua regulação exige que, sem substituir a iniciativa privada, o Estado aprimore a sua capacidade "de intervir no mercado de alimentos, seja na indução da concorrência nos setores oligopolizados, seja na inibição de práticas especulativas presentes, sobremaneira nos mercados atacadistas de produtos agroalimentares".

Nessa perspectiva, o município pode intervir no sentido de estimular o aumento da oferta de alimentos e a concorrência entre comerciantes, visando a uma redução dos preços finais e à melhoria da qualidade dos alimentos comercializados. Nesse sentido, o Estado atua induzindo à concorrência ou inibindo possíveis práticas abusivas. Esse tipo de política tem sido implementado em vários municípios, principalmente nos grandes centros urbanos, onde são disponibilizados espaços públicos para o comércio de alimentos. Entretanto, para que os comerciantes se instalem nestes locais, devem aceitar algumas pré-condições como, por exemplo, estabelecer preços abaixo das cotações do mercado local, levando a um aumento relativo do poder de compra dos consumidores.

Lavinas e Nabuco (1991) compreendem que uma política de intervenção pode desmistificar a visão neoliberal de crença na capacidade das leis de mercado, até então definidora das ações governamentais, contrapondo-se, portanto, tanto à visão de que o jogo do mercado seria suficiente para promover um estado ótimo de abastecimento, quanto à idéia de que suas falhas podem ser compensadas satisfatoriamente pelas políticas sociais focalizadas.

Assim, as políticas de abastecimento alimentar podem atuar no mercado local, abranger uma grande parte da população e levar outros comerciantes a baixarem seus preços. O pressuposto central aqui é de que qualquer pessoa poderia comprar os alimentos nos equipamentos públicos, não havendo qualquer discriminação quanto a critérios para o seu acesso. No entanto, essa mesma política é excludente aos que não dispõem de recursos para a compra dos alimentos, uma parcela assustadoramente grande da população, que não poderá acessar os 
alimentos por meio dos mercados. Torna-se necessário desenvolver políticas específicas para garantir o acesso destas pessoas à alimentação, seja por meio de políticas e mecanismos que incentivem a produção para o autoconsumo - mesmo nas grandes capitais tem se estimulado a produção em pequenos espaços -, ou por meio de políticas de assistência alimentar que disponibilizem alimentos a grupos específicos que não conseguem satisfazer adequadamente nem suprir suas necessidades alimentares e nutricionais pelo mercado ou por meio de produção para o auto-consumo. As políticas de assistência alimentar compreendem, ainda, as ações de complementação alimentar ou de reforço para aqueles que conseguem suprir parcialmente suas necessidades.

Geralmente, nas políticas de assistência alimentar, não há qualquer dispêndio para os beneficiários que se enquadram em critérios ou categorias consideradas prioritárias para atendimento como, por exemplo, de crianças na fase de aleitamento, de gestantes, de estudantes (merenda escolar) etc. Os recursos para a execução dessas ações têm origem tanto no governo federal quanto no próprio orçamento municipal.

Entretanto, as especificidades inerentes ao campo da segurança alimentar e nutricional, aliadas à complexidade da implementação das políticas públicas, têm provocado, segundo vários especialistas, equívocos na gestão e operacionalização destas políticas. Para começar, seu público-alvo é extremamente fragmentado e disperso, o que dificulta a efetividade dessa política, sua operacionalização e avaliação.

Lavinas e Nabuco (1996) avaliam que as ações e as políticas sociais na área alimentar foram pautadas pela falta de planejamento e pulverização dos recursos em projetos, muitas vezes superpostos e não-complementares. Freqüentemente, a preocupação com a eficácia política dos programas prevalece sobre o interesse coletivo. Em muitos casos, o aumento do número de beneficiários, com uma perspectiva de ganho político, significa diminuição do valor de benefícios per capita, colocando em risco a qualidade e os resultados.

A ausência de vínculos e interfaces entre as diferentes áreas de ação das políticas sociais, como saúde, educação e abastecimento, entre outras, resulta em um número ainda maior de pessoas atendidas em diferentes programas, minimizando sua eficiência, o que, com recursos escassos, leva à dificuldade de manutenção de tais programas.

Dessa forma, Gomes Jr. (2002) entende que as diretrizes para uma política municipal de segurança alimentar devem refletir, na orientação do arranjo de programas e ações desenvolvidas sob sua égide, o compromisso de operar articuladamente com outras políticas sociais, na direção do resgate da cidadania, confiscada da maioria da população, fortalecendo a organização popular, desbloqueando os limites institucionais que inibem e impedem a participação e o controle dos cidadãos sobre seu próprio futuro.

Maluf (2001) observa que as políticas de segurança alimentar possuem interfaces evidentes com outras políticas implementadas nos municípios, de modo que a segurança alimentar passa a figurar ao lado dos outros objetivos que ordenam as políticas e programas municipais. $\mathrm{O}$ autor destaca, ainda, a necessidade de criar um espaço institucional para a coordenação de políticas e programas que tenham relação com o objetivo da segurança alimentar, espaço este que deve contar com a participação da sociedade na formulação e na implementação das ações voltadas para este objetivo.

A implementação de políticas na área alimentar exige esforços no sentido de prevenir a influência negativa das forças políticas do capital privado, como na prevalência de interesses particulares, os quais são comumente exercidos sobre as administrações municipais, o que facilita a apropriação de recursos por grupos econômicos e de beneficiários que nem sempre são o público-alvo de determinada ação. Para isso, no entanto, são exigidas dos executores, disposição e vontade política para enfrentamento dos grupos de pressão com o objetivo de adequar as estruturas locais ao atendimento das reais necessidades da população.

Ao mesmo tempo em que é preciso que se tomem alguns cuidados para que não haja este tipo de apropriação indevida das ações governamentais, a administração pública não pode prescindir da articulação com os atores locais, principalmente em virtude do quadro de precariedade pelo qual passa o serviço público. Dessa forma, Farah $(2001,141)$ considera que, 
[...] a redefinição da esfera pública inclui também a construção de novos arranjos institucionais, que superam o modelo de provisão estatal e o padrão uniorganizacional centralizado que caracterizava o período anterior [o da constituição de 1988]. Tais arranjos apontam para a construção de redes institucionais que reúnem diversos atores, envolvendo articulações intersetoriais, intergovernamentais e entre Estado, mercado e sociedade civil.

Assim, além desta articulação que se pode chamar de 'entre setores', há uma crescente necessidade de articulação do setor público com a sociedade civil e o setor privado, como forma de viabilizar a implementação de tais políticas e de concebê-las de forma a estarem mais próximas dos interesses e necessidades da população. A intersetorialidade é uma alternativa, tanto para a maior eficiência na aplicação de recursos como no desenvolvimento das políticas públicas, superando a fragmentação perniciosa comum nas políticas sociais.

Por sua vez, Menicucci (2002) considera a intersetorialidade uma nova maneira de abordar os problemas sociais, enxergando o cidadão em sua totalidade e estabelecendo uma nova lógica para a gestão da cidade, superando a forma segmentada e desarticulada como em geral são executadas as diversas ações públicas: encapsuladas nos vários nichos setoriais que se sobrepõem às subdivisões profissionais ou disciplinares. Significa tanto um esforço de síntese de conhecimentos como de articulação de práticas, em que se busca unificar o modo de produção de conhecimento e as estratégias de ação, tendo como meta a inclusão social.

Farah (2001) considera importante que os governos locais assumam papel de coordenação e de liderança, mobilizando atores governamentais e não-governamentais e procurando estabelecer um processo de "concertação" de diversos interesses e de diferentes recursos em torno de objetivos comuns. Por meio dos novos arranjos institucionais assim constituídos, tende a crescer a perspectiva de sustentabilidade de políticas públicas que, de outra forma, poderiam sofrer interrupções a cada mudança de governo. O enraizamento das políticas em um espaço público que transcende a esfera estatal reforça a possibilidade de políticas de longo prazo, com repercussões sobre a eficiência e a efetividade das políticas implantadas.

Embora tais arranjos na elaboração e na implementação de políticas públicas sejam importantes, é necessária uma definição clara dos papéis dos diferentes atores envolvidos. Mesmo assim, há questionamentos de autores, como Burlandy $(1999,66)$, sobre a eficácia das parcerias entre diferentes instituições e setores em relação ao atendimento das necessidades dos beneficiários ou, nas palavras da autora: "é preciso questionar se esta capilaridade também se traduz em termos de vocalização das demandas reais dos beneficiários da política".

No entanto, não é tarefa fácil transpor as fronteiras setoriais constituídas dentro e fora das instituições públicas. $\mathrm{Se}$, teoricamente, a intersetorialidade se apresenta como uma alternativa lógica e possível - até porque as ligações entre diferentes áreas de ação das políticas e problemas sociais se apresentam de forma relativamente clara -, na prática, a implementação de políticas que incorporem a noção de intersetorialidade é difícil.

Menicucci (2002) ressalta, ainda, que as resistências a ações integradas no âmbito das políticas públicas de diferentes origens são previsíveis uma vez que: pressupõem deslocamentos de poder, de deliberação e de campos do saber; demandam modificações nos processos de trabalho e, principalmente, nas concepções e valores arraigados sobre como fazer a coisa certa; interesses corporativos menores podem ser afetados, uma vez que o pólo dinâmico das prefeituras se desloca do centro para a periferia, e até os movimentos populares necessitam mudar suas práticas organizadas, na maioria das vezes, a partir de recortes setoriais em observância à própria legislação brasileira.

Trata-se, de fato, de mudança de concepção que suscita o mesmo na cultura organizacional e nas práticas institucionalizadas no desenvolvimento da cooperação e da parceria. Para enfrentar esse desafio de mudar o padrão de eficácia das políticas sociais, é imprescindível a formação de alianças entre todos que querem melhorar a qualidade de vida dos cidadãos, localizados dentro e fora da administração pública: dirigentes, técnicos, prestadores e usuários dos serviços. 
A idéia de transversalidade que perpassa mais recentemente os debates sobre políticas de segurança alimentar aparentemente está vinculada a esta noção de intersetorialidade. A eficácia destas mudanças, entretanto, depende de que a proposta seja uma construção coletiva (MENICUCCI, 2002; BURLANDY, 2003) e de um projeto politicamente consistente (BURLANDY, 2003).

Os conflitos e as alternativas inerentes ao esforço de promover tais mudanças na esfera pública municipal têm peculiaridades em cada local. A seguir, se discutirá como este processo se deu no município de Belo Horizonte, desde os primeiros movimentos, com a vitória de partidos de esquerda nas eleições para a prefeitura e, mais especificamente, no período que vai de 1993 a 2003.

Articulações institucionais e setoriais nos programas Abastecer e Alimentação Escolar da prefeitura de Belo Horizonte

A partir de 1993, a administração municipal de Belo Horizonte, por meio da Secretaria Municipal de Abastecimento (SMAB), delineou suas políticas na área alimentar, adotando uma perspectiva de segurança alimentar, ou seja, atuando nas áreas de produção de alimentos, defesa e promoção do consumo alimentar e na comercialização de alimentos. Na concepção da política de segurança alimentar do município, foram incorporados novos programas e aqueles que já existiam sofreram reformulações que, em 2003, chegaram a 24 programas.

Para implementar tal política, com grande diversidade de linhas de ação, a Secretaria estabeleceu uma rede de instituições e parceiras que envolvem entidades públicas e privadas, produtores rurais e organizações sociais. Pessoa e Machado (1999) estimaram que os programas na área de segurança alimentar de Belo Horizonte envolviam cerca de 838 parceiros e permissionários.

A SMAB passou a desenvolver, assim, uma articulação institucional e também intersetorial na coordenação de programas que antes estavam dispersos em outras áreas da administração municipal. Na avaliação de representantes do poder público, funcionários da secretaria, esta articulação foi fundamental para se chegar aos resultados alcançados pela SMAB neste período. No entanto, a construção das articulações ocorreu de maneira diferenciada nos programas desenvolvidos na secretaria municipal, que envolvem beneficiários, parceiros e objetivos diferentes e podem ser classificados em duas categorias: programas de regulação de mercado e programas de assistência alimentar.

Enquanto nos programas de regulação de mercado desenvolveram-se predominantemente parcerias com instituições privadas e ligadas ao mercado, os programas de assistência alimentar basearam-se numa forte articulação intersetorial (com outros setores da administração municipal), tais como educação, saúde, desenvolvimento social etc. e com órgãos em outros níveis de governo, organizações sociais etc. Tais diferenças nos levam a promover uma discussão sobre a articulação em cada um destes programas separadamente. Uma vez que a SMAB envolve diversos programas, alguns muito amplos que podem ser abarcados nestas classificações, optou-se por focalizar apenas algumas experiências locais em cada categoria: o programa Abastecer, como uma iniciativa de regulação de mercado e o programa de Alimentação Escolar, como exemplo de programa de assistência alimentar.

\section{O programa Abastecer}

O programa Abastecer foi instituído em 1993, a partir da reestruturação do antigo programa $\mathrm{ABC},{ }^{3}$ do qual extraíram-se algumas concepções centrais, como, por exemplo, o objetivo de reduzir os preços dos alimentos para as populações de baixa renda e a forma de comercialização (tipo sacolão).

O programa Abastecer prevê a disponibilização de uma área pela Prefeitura para a iniciativa privada instalar o equipamento e explorar comercialmente o ponto. Por sua vez, os comerciantes selecionados para o programa se comprometem a vender 25 variedades de hortigranjeiros, com uma margem fixada tendo por base os preços do produto no atacado. 
Para a gestão e execução do programa, foram estabelecidas várias parcerias com órgãos da administração pública municipal, da sociedade civil e da iniciativa privada. No Abastecer, as administrações regionais participam de sua execução, acompanhando o processo desde o início da implantação dos pontos de comercialização do programa, verificando a disponibilidade de imóvel ou espaço público para instalação dos equipamentos e fiscalizando as atividades de comércio informal ao redor dos equipamentos, bem como a documentação dos permissionários para o exercício da atividade.

Por meio de um processo de licitação, é escolhido o comerciante que terá a permissão de uso (permissionário) e que se responsabilizará pela construção das instalações. A relação entre permissionários e SMAB é regulada, por contrato, pelo período de um ano, com possibilidade de prorrogação.

Na operacionalização deste programa, o CEASA-BH é também um parceiro fundamental, pois repassa semanalmente as cotações no mercado atacadista que servem de base para o cálculo dos preços cobrados nos equipamentos do Abastecer.

No processo de reestruturação do programa Abastecer, a SMAB assumiu um novo tipo de comportamento com relação aos permissionários, não exercendo somente a fiscalização, mas também orientando os parceiros quanto a higiene, limpeza do local, exposição de produtos etc. A administração municipal passa, assim, a atuar de forma mais educativa do que punitiva - o que, segundo depoimentos de funcionários da prefeitura e permissionários, contribuiu para tornar menos freqüentes os conflitos com estes parceiros.

Mesmo assim, a definição dos preços ainda é o tema que gera maior tensão na relação entre os permissionários e a SMAB. Dependendo da sazonalidade dos produtos, quebra de safra ou mudanças na própria conjuntura econômica, os permissionários reúnem-se com a SMAB para discutir os preços praticados nos equipamentos do Abastecer.

A implantação destes equipamentos tem possibilitado a redução dos preços de vários produtos, estimulando o consumo de alimentos de qualidade e saudáveis pela população do município. Nesse sentido, trata-se de uma política mais geral que atinge um grande número de pessoas de diversos perfis, resultados que foram conquistados por meio de parcerias entre setores público e privado e que recebem, também, algumas críticas.

A principal crítica ao programa avalia a relação entre SMAB e permissionários como uma apropriação pelo capital privado de equipamentos estatais - pois estes ocupam e exploram comercialmente uma área pública. No entanto, o papel ativo de regulação do Estado sobre o mercado e os resultados obtidos pelo programa podem ser considerados como o que Farah (2001) compreende como uma substituição do modelo de provisão estatal por um modelo em que o Estado deixa de ser o provedor direto exclusivo e passa a ser o coordenador e fiscalizador de serviços que podem ser prestados pelo mercado ou em parceria com este setor, sem, no entanto, transferir um patrimônio e a responsabilidade pública à iniciativa privada.

Diante da escassez de recursos públicos para investimentos, bem como de toda a complexidade da gestão e operacionalização dos aparelhos como os do programa Abastecer, estabelecer parcerias com o setor privado pode ser uma forma eficiente de viabilizar projetos de interesse da sociedade.

Segundo Silva (2000), a transformação política do município envolve, ainda, o estabelecimento de uma nova relação entre o Estado e o setor privado. Mesmo para aqueles municípios que obtiveram significativos ganhos com a Constituição de 1988 - em particular as capitais -, a necessidade não só de assumir a função de welfare, mas também do estímulo ao desenvolvimento econômico local, torna fundamental o incremento das parcerias com a iniciativa privada.

Esta reconfiguração da relação entre o público e o privado, estabelecida nos programas de segurança alimentar e abastecimento do município de Belo Horizonte com a criação da SMAB, também pode ser entendida como reflexo de uma mudança no foco da política. É possível identificar uma mudança na gestão dos programas com a redução da ênfase nas atividades-meio, característica de um modelo burocrático, e maior atenção ao 
atendimento à população. Com isso, os programas ganharam maior flexibilidade, necessária para ajustá-los às mudanças conjunturais da economia e da própria sociedade, sem perder, contudo, seus objetivos principais.

É claro que há muitos riscos neste processo, por isso deve haver transparência nos processos de licitação e uma fiscalização que garanta efetivamente a qualidade dos produtos ofertados. A institucionalização da proposta e o desenvolvimento de mecanismos de monitoramento e avaliação do programa são elementos essenciais.

O programa Abastecer passa por um processo de monitoramento que procura avaliar os resultados e benefícios para a população. Para isso, conta, novamente, com as parcerias estabelecidas com instituições de pesquisa que auxiliaram na definição da metodologia de pesquisa, na estruturação dos dados a serem coletados e na divulgação destas informações. Dificilmente a SMAB ou a prefeitura municipal teriam totais condições para a elaboração de estudos desta natureza.

A articulação com instituições acadêmicas, inclusive com algumas fora do âmbito municipal, teve um importante papel, tanto para o monitoramento e a avaliação dos programas, quanto para dar maior visibilidade aos programas e projetos desenvolvidos pela secretaria. Esta articulação do poder público local com universidades e instituições de pesquisa foi facilitada pela proximidade de alguns dos integrantes da equipe da SMAB com a comunidade acadêmica.

Em virtude da existência de poucas áreas no município para a instalação de novos equipamentos de comercialização, o programa Abastecer passou a compartilhar alguns espaços com o projeto Direto da Roça, que estimula agricultores da região e de outros municípios a comercializarem sua produção diretamente para consumidores de Belo Horizonte. O projeto Direto da Roça ${ }^{4}$ comercializa produtos frescos, sem uso de agrotóxicos, vindos do interior do estado. Estabeleceu-se um acordo, entre os atores interessados, de que a comercialização de folhosas seria de responsabilidade dos agricultores do programa Direto da Roça, que poderiam oferecer produtos frescos todos os dias e os demais produtos do programa Abastecer, estabelecendose uma certa complementaridade entre os programas.

O projeto Direto da Roça, bem como outros que fazem parte do programa de produção e venda direta ao consumidor da $\mathrm{SMAB},{ }^{5}$ despertam interesses nas prefeituras do interior, pois possibilitam o escoamento da produção de sua região. Estas iniciativas são também significativas do ponto de vista da segurança alimentar, estimulando a produção agrícola sem agrotóxico e também o desenvolvimento regional, assegurando ao agricultor uma renda mensal mais elevada do que a que obteria se tivesse que negociar com um atravessador.

Embora sejam perceptíveis articulações entre programas e projetos no âmbito da SMAB, as articulações setoriais da área de abastecimento e segurança alimentar com outras áreas (saúde, educação, habitação, trabalho etc.), nos programas de regulação de mercado, são menos visíveis (embora não menos importantes) do que, como se discutirá, nos programas de assistência alimentar.

As articulações, essenciais para se levar adiante os programas de regulação de mercado, são fortemente caracterizadas por vínculos contratuais (o caso dos permissionários) ou estabelecidas entre instituições públicas com interesses afins, como é o caso da EMATER-MG e prefeituras do interior ou a CEASA-MG. Além disso, cabe ressaltar a importância da transparência nas relações existentes nestas parceiras, principalmente nos processos de licitação e escolha dos permissionários, bem como na definição dos critérios utilizados para o estabelecimento dos preços praticados nos equipamentos.

\section{Articulações nos programas de assistência alimentar}

Os programas de assistência alimentar envolvem uma série de ações voltadas para aquelas parcelas da população com maiores carências nutricionais e para atender a grupos de pessoas em situações de risco, como os atingidos por enchentes e deslizamentos, que demandam ações emergenciais. Um dos objetivos deste programa é priorizar pessoas que estão vivenciando o que alguns denominam 'ciclos prioritários', como 
gestantes, crianças, adolescentes e idosos, cujas necessidades alimentares e nutricionais são bastante específicas.

Além de projetos específicos para estes grupos, o programa de assistência alimentar é responsável por projetos de comercialização subsidiada, como o restaurante popular e o cestão popular. Entretanto, neste artigo, o foco estará no Projeto de Alimentação Escolar, que é parte do Programa de Alimentação de Crianças e Adolescentes.

O Programa de Alimentação de Crianças e Adolescentes é o maior programa da SMAB na área de assistência alimentar. Nele estão incluídos três projetos: a) o Projeto de Prevenção e Combate à Desnutrição, desenvolvido em parceria com a Secretaria de Saúde e por meio do qual são distribuídos mensalmente alimentos e farinha enriquecida para gestantes, nutrizes e crianças desnutridas; b) o Projeto de Assistência Alimentar e Nutricional que, em parceria com a Secretaria Municipal de Desenvolvimento Social, fornece gêneros alimentícios para entidades conveniadas que atendem meninos e meninas com trajetórias de rua, portadores de deficiência, Centros de Apoio Comunitário (CAC) e desenvolvem trabalhos de reforço escolar, recreação e profissionalização de adolescentes; e c) o Projeto de Alimentação Escolar, que atende alunos matriculados nos ensinos fundamental e médio e nas creches conveniadas com o município - seus recursos são provenientes do Governo Federal e da Prefeitura de Belo Horizonte.

Com o processo de descentralização do Programa de Alimentação Escolar, maiores responsabilidades foram atribuídas aos municípios, que tiveram de se adaptar às exigências legais e também disponibilizar contrapartidas, como infra-estrutura e pessoal, para a efetivação do programa. Assim, Arretche (2000) avalia que, em um processo de transferência de atribuições, a capacidade técnica instalada constitui um fator determinante para que as agências do governo consigam assumir o exercício de determinadas funções.

Até o ano de 1993, a alimentação escolar estava sob a responsabilidade da Secretaria de Educação de Belo Horizonte, sendo transferida gradualmente para a SMAB. Nesse processo de transferência, que envolveu, e ainda envolve, dois setores, foram incluídos aos poucos novos atores, à medida que o programa se reestruturava.

A estrutura criada pela SMAB (pessoal técnico, setor de compras, planejamento, etc.) para gerenciar a alimentação escolar também serviu para o desenvolvimento de outros programas, aumentando e melhorando o atendimento aos beneficiários, inclusive de outros programas. Por exemplo, a introdução de produtos in natura na alimentação escolar e o planejamento nutricional das refeições servidas são práticas que foram estendidas também a projetos envolvendo creches e asilos, utilizando-se da mesma estrutura criada para a alimentação escolar. Esta estrutura atende também a projetos desenvolvidos por outros parceiros, como o projeto Minguilim e Dente de Leite (voltados para crianças e adolescentes), gerenciados pela Secretaria do Desenvolvimento Social.

Para atender aos estudantes da rede pública, com um quadro de pessoal relativamente pequeno, a SMAB passou a terceirizar alguns serviços (principalmente as cantineiras que elaboram as refeições servidas nas escolas), além de utilizar pessoal de outros órgãos da prefeitura, graças à articulação entre setores.

A articulação intersetorial também contribuiu para que a SMAB conseguisse implementar seus programas sem a necessidade de aumentar demasiadamente sua estrutura. Nesse aspecto foi fundamental a articulação com a Secretaria do Desenvolvimento social, pois é ela quem realiza os convênios com as creches, entidades filantrópicas e o cadastro de famílias carentes do município.

Para Pessoa e Machado (1999), um ensinamento que se extrai da experiência em Belo Horizonte é que a estrutura não precisa ser grande para a implantação de projetos na área de segurança alimentar. A SMAB é pequena em orçamento, em pessoal e em espaço físico. No entanto, é grande onde precisa sê-lo, ou seja, na política que produz e distribui serviços para a comunidade. Para crescer, a secretaria dialoga com outros órgãos e programas públicos, com o setor privado, filantrópico e com a comunidade em geral. Dessa forma, além de 
cumprir com seus objetivos no que se refere à segurança alimentar, a política atua de forma indireta na área de geração de emprego e renda, na qualificação de mão-de-obra para o mercado de trabalho, no desenvolvimento de tecnologias simplificadas e ecologicamente sustentáveis de alimentos e produtos alimentícios, na fixação da família no campo etc.

Apesar de todo o esforço e da reestruturação da SMAB para acolher o programa de alimentação escolar e de alguns bons resultados alcançados nesta transição, o projeto de Alimentação Escolar em Belo Horizonte sofreu, nos últimos anos, uma redução na disponibilidade financeira para a compra de alimentos. Trata-se, na verdade de um problema nacional, pois, o Fundo Nacional de Desenvolvimento Escolar (FNDE) repassava um valor fixo, no período de 1993 a 2003 (época da pesquisa), de R \$ 0,13/aluno/dia, ${ }^{6}$ para as prefeituras executarem o programa. Evidentemente, neste período de 10 anos, os preços dos alimentos foram reajustados várias vezes, criando dificuldades na compra de alimentos para a merenda escolar. Verificava-se até mesmo o comprometimento do atendimento da exigência feita pelo próprio FNDE de que a merenda escolar deve suprir, pelo menos, $15 \%$ das necessidades diárias de alimentação de crianças e adolescentes do ensino fundamental, uma vez que os custos per capita da alimentação escolar no município estavam, em 2003, em torno de $\mathrm{R} \$ 0,20$.

Se, por um lado, a articulação local foi de importância crucial para a implementação deste programa de Assistência Alimentar no município de Belo Horizonte, a falta de articulação entre o governo federal e os governos estaduais e municipais criou outros problemas para a gestão deste e de outros programas. O Governo Federal, que, em tese, é parceiro dos municípios na implementação da merenda escolar, restringe sua participação com o repasse de recursos insuficientes para o funcionamento do programa. Outro fator que ilustra essa falta de articulação (que também não é problema exclusivo do município de Belo Horizonte) é o de que existe uma duplicidade nas ações no atendimento da alimentação escolar, pois as escolas estaduais são atendidas pela Secretaria Estadual de Educação, que optou pela chamada "escolarização da merenda", uma alternativa que dá maior autonomia às escolas. Independentemente do resultado obtido no programa de Alimentação Escolar, que é coordenado pelo governo do estado, essa duplicidade nas ações provoca perdas tanto nos "ganhos de escala" para a aquisição dos gêneros alimentícios, como na possibilidade de uma ação mais coordenada e de um controle mais efetivo de saúde alimentar das crianças do município.

A construção de tantos tipos de articulações não diminuem a importância do papel da SMAB na coordenação das políticas de segurança alimentar de Belo Horizonte, que partem do princípio da alimentação como direito básico, e também contemplam as diferenças de acesso da população a esse direito. Nesse sentido, há uma articulação também entre as políticas de caráter universal, como é o caso das políticas de abastecimento e as políticas focalizadas.

\section{Conclusões}

A princípio, neste texto, procurou-se demonstrar, por meio de um caso específico, as possibilidades existentes para a construção de uma política pública compartilhada entre diversos atores que se mobilizaram em torno de uma proposta de ação municipal de segurança alimentar e nutricional. Os limites dessa reflexão são evidentes, uma vez que não se podem ampliar as conclusões deste caso para a implementação de outras políticas e programas municipais de segurança alimentar, por não ser possível estabelecer um desenho institucional capaz de contemplar todas as situações encontradas na grande diversidade de municípios que existem no país. Entretanto, algumas dessas reflexões podem ser úteis em outros casos.

Os programas de segurança alimentar em Belo Horizonte valeram-se das potencialidades existentes na localidade e estabeleceram uma forte articulação, tanto institucional como setorial. Na articulação institucional, observada mais fortemente nos programas de regulação de mercado, identifica-se a construção de relações com alguns atores sociais, com o objetivo de ampliar o campo de atuação da SMAB e otimizar os recursos empregados em cada programa. Assim, foram constituídas parcerias com agentes de mercado (Ceasa-MG, comerciantes, fornecedores etc.) e da sociedade civil (associações de bairro, por exemplo) com outras instituições púbicas (prefeituras, EMATER etc.) e com centros de pesquisas (como IPEAD, UFMG e PUC). 
As articulações institucionais e intersetoriais contribuíram para a ampliação do atendimento à população e, mesmo nos programas focalizados, houve um esforço também nesse sentido, aproveitando e otimizando a estrutura existente, como no caso da alimentação escolar e dos outros programas similares de assistência alimentar.

A articulação setorial, característica mais marcante nos programas de assistência alimentar, foi igualmente importante na formulação e na implementação dos programas desenvolvidos pela SMAB. Assim, a integração das diversas secretarias municipais (Educação, Saúde etc.) em torno de programas comuns, permitiu maior abrangência de suas ações, ganhos de escalas no atendimento, melhor aproveitamento dos recursos investidos e, principalmente, melhoria na qualidade do atendimento à população.

A necessidade de uma gestão que integre diversas esferas governamentais, setores públicos, agentes de mercado e da sociedade civil para implementação de uma política de SAN é um grande desafio à administração pública, uma vez que a solução para os problemas ligados a essa área não pode esperar o tempo e a lógica do Estado. Necessita-se, sim, de ações que produzam resultados eficientes, caso contrário, podem causar efeitos irreversíveis à saúde pública.

Embora a focalização e universalização sejam colocadas, em muitos casos, como processos antagônicos e às vezes excludentes; na perspectiva das políticas locais de segurança alimentar, em Belo Horizonte elas adquirem um sentido de complementaridade. Assim, a SMAB procurou ampliar sistematicamente o atendimento nos programas focalizados, como mencionado anteriormente, fazendo uso da estrutura existente (compras, pessoal técnico, armazenagem e distribuição para a alimentação escolar) e da articulação com outros setores da administração municipal (secretarias de saúde, desenvolvimento social, educação etc.), sem necessidade de grandes volumes de investimento, otimizando os recursos existentes.

A utilização do critério de focalização pôde ser aplicada para atender aos diferentes grupos com características e necessidades próprias. As articulações setoriais foram importantes para que um maior número de beneficiários pudesse ser atendido, não se restringindo apenas aos recursos financeiros disponíveis, utilizandose de estruturas operacionais existentes, tanto materiais (instalações e equipamentos) como sociais (grupos, associações, serviços públicos etc.).

Assim, a focalização justifica-se como um instrumento para melhorar o atendimento aos grupos mais necessitados, minimizando os problemas decorrentes da escassez de recursos e baixa capacidade operacional dos governos municipais, tão comuns no país.

No caso apresentado, a combinação das políticas focalizadas com a busca da universalização das políticas de abastecimento, foi possível mediante articulações com outros setores, o que possibilitou, com uma estrutura relativamente enxuta, ampliar $\mathrm{o}$ atendimento à população.

O resultado dos esforços para a realização dessas articulações setoriais e institucionais e para a superação de algumas dificuldades iniciais, traduz-se, hoje, no ganho de experiência que a secretaria acumulou na solução de problemas e conflitos e também no aprendizado organizacional, que proporciona maior agilidade às tomadas de decisão, critérios mais transparentes na relação entre parceiros, permissionários e beneficiários dos programas.

Há, ainda, dificuldades a serem superadas nas relações com os parceiros, mesmo porque a dinâmica própria da política municipal não gira apenas em torno da política de segurança alimentar; ela é condicionada também por outras disputas e interesses que vão além da área de atuação da SMAB; mas, o aprendizado obtido com as relações favorece a superação dos problemas com maior agilidade e objetividade.

Por outro lado, a articulação com outros níveis de governo revelou-se, principalmente na análise do programa de assistência alimentar, uma relação bastante conflituosa, com isolamento de alguns níveis e superposição de ações que comprometem o bom desempenho dos programas e, em última instância, o atendimento à população. 


\section{Referências}

ABRANCHES, S. H.; SANTOS, W. G.; COIMBRA, M. A. Política social e combate à pobreza. 4. ed. Rio de Janeiro: Jorge Zahar Editor, 1998.

ARRETCHE, M. Estado federativo e políticas sociais: determinantes da descentralização. Rio de Janeiro: Revan; São Paulo: FAPESP, 2000.

BRESSER PEREIRA, L. C. Gestão do setor público: estratégia e estrutura para um novo Estado. In: BRESSER PEREIRA, L. C.; SPINK P. K. Reforma do Estado e administração pública gerencial. Rio de Janeiro: Editora FGV, 1999.

BURLANDY, L. Os desafios do gestor municipal para o alcance da segurança alimentar. Revista Saúde em Foco, Rio de Janeiro, Ano VIII, n. 18, jul. 1999. Secretaria Municipal de Saúde 1999.

Segurança alimentar e nutricional e intersetorialidade. Segunda Conferência Estadual de Segurança Alimentar e Nutricional Sustentável de Minas Gerais. Belo Horizonte, 2003.

DRAIBE, S. M. A construção institucional da política brasileira de combate à pobreza: perfis, processos e agenda. Campinas: Caderno de Pesquisa n. 34, Unicamp, 1998.

DREZE, J.; SEN, A. Hunger and public action. New York: Oxford University Press, 1989.

FARAH, M. F. S. Parcerias, novos arranjos institucionais e políticas públicas no nível local de governo. Revista de Administração Pública, Rio de Janeiro, v. 35, n. 1, p. 119-144, jan./fev. 2001.

GODOY, A. S. Estudo de caso qualitativo. In: GODOI, C. K.;BANDEIRA-DE-MELLO, R.; SILVA, A. B. (Orgs.). Pesquisa qualitativa em estudos organizacionais: paradigmas, estratégias e métodos. São Paulo: Saraiva, 2006, p. 115-146.

GOMES JR., N.N. Sistema municipal de segurança alimentar e cidadania: limites e desafios para os governos locais. In: TAKAGI M.;SILVA, J. G.; BELIK, W. (Orgs.). Combate à fome e à pobreza rural. São Paulo: Instituto da Cidadania, 2002.

LAVINAS, L.; MALUF, R. S. Abastecimento, segurança alimentar e ação municipal. IBAM/Revista de Administração Municipal, Rio de Janeiro, v. 39, n. 203, p. 63-70, 1992.

LAVINAS, L.; NABUCO; M. R. Crise, abastecimento e uso do solo. CNPQ - Relatório Parcial IV: Abastecimento: Histórico e atualidade - Auxílio Integrado à Pesquisa, 1991.

- Segurança Alimentar: uma nova questão de cidadania. In: CAVALCANTI, J. E. A.; VIEIRA, W. C. Política Agrícola e Segurança Alimentar. Minas Gerais: Universidade Federal de Viçosa, 1996.*

MALUF, R. S.; COSTA, C. Diretrizes para uma política municipal de segurança alimentar e nutricional. São Paulo: Polis, 2001. (Publicação Polis 38).

MENICUCCI, T. M. G. Intersetorialidade, o desafio atual para as políticas sociais. Revista Pensar BH. Belo Horizonte, Secretaria Municipal de Coordenação de Política Social. Edição temática n. 3 - maio/jul. 2002.

PESSOA, M. J. S.; MACHADO, M. Relatório de atividades. Belo Horizonte: Secretaria Municipal de Abastecimento, Documento Interno, 1999.

PINHO, J.A.G. de.; SANTANA, M. W. O que faz o governo municipal no Brasil? Realizações, tendências e perspectivas. Encontro da Associação Nacional dos Programas de Pós-graduação em Administração. Anais... 24, 2000, Florianópolis.

SANTOS, W. G. A trágica condição da política social. In: ABRANCHES, S. H.; SANTOS, W. G.; COIMBRA, M. A. Política social e combate à pobreza. 4.ed. Rio de Janeiro: Jorge Zahar Editor, 1998.

SILVA, R. V. A. da. Descentralização e municipalização: a redefinição do papel do Estado no âmbito local. Encontro da Associação Nacional dos Programas de Pós-graduação em Administração. Anais... 24, 2000, Florianópolis. 
WILSON, E. Hambruna e pobreza em el siglo 21. In: PINSTRUP-ANDERSEN; PANDYA-LORCH, R. La agenda inconclusa: Perspectivas para superar el hambre, pobreza y la degradación ambiental. Instituto Internacional de Investigación sobre Políticas Alimentárias. Washington, D.C. 2002.

${ }^{1}$ A proposta de reforma do Estado foi remetida ao Congresso em 1995, e em 1996 foi publicado o Plano Diretor da Reforma Administrativa do aparelho do Estado.

2 O documento brasileiro apresentado à Cúpula Mundial da Alimentação, em 1996, assim definiu a Segurança Alimentar e Nutricional: "garantir a todos, condições de acesso a alimentos básicos de qualidade, em quantidade suficiente, de modo permanente e sem comprometer o acesso a outras necessidades essenciais, com base em práticas alimentares saudáveis, contribuindo, assim, para uma existência digna, em um contexto de desenvolvimento integral da pessoa humana".

${ }^{3}$ Para Coelho (1999), o Programa Abastecer representa uma retomada do antigo Programa ABC e seu novo nome é apenas "logomarca" do programa, que se utiliza, ainda, para uso legal, da mesma lei que criou o ABC. Inspira-se também na mesma constatação que, em 1976, foi utilizada para justificar, perante a Câmara de Vereadores, a sua criação: a de que Belo Horizonte, em virtude da ação dos intermediários, apresentava índices de preços ao consumidor dos mais altos do país, sendo necessária, portanto, a intervenção no mercado, para reduzir os preços dos alimentos de maneira a torná-los acessíveis ao consumidor pobre.

${ }^{4}$ Para coordenar esse programa, a SMAB montou uma equipe para visitar propriedades e estruturar a comercialização. Conta também, nesse trabalho, com a colaboração da EMATER-MG, que possui estrutura por todo o estado e das prefeituras municipais do interior do estado.

${ }^{5}$ Há, ainda, dentro desse programa, especializações, como o Campanha de Safra, Armazém da Roça, Bolsa Verde, Central Municipal e hortas comunitárias.

${ }^{6}$ Atualmente, o valor do repasse é de $\mathrm{R} \$ 0,18$ por aluno da educação infantil, do ensino fundamental e de creches públicas e filantrópicas. 